\title{
Comparative in vitro assessment of tolterodine tartrate tablets by high performance liquid chromatographic (HPLC)
}

\author{
Hossein Danafar ${ }^{1,2}$ \\ ${ }^{1}$ Zanjan Pharmaceutical Nanotechnology Research Center, Zanjan University of Medical Sciences, Zanjan, Iran \\ ${ }^{2}$ Department of Medicinal Chemistry, School of Pharmacy, Zanjan University of Medical Sciences, Zanjan, Iran

\begin{abstract}
Tolterodine tartrate, is a new, potent and competitive muscarinic receptor antagonist in clinical development for the treatment of urge incontinence and other symptoms of unstable bladder. The purpose of this study is to establish a reliable and quick method for the assignment of tolterodine tartrate by high performance liquid chromatography with ultraviolet detection (HPLC-UV). A rapid and sensitive high performance liquid chromatographic (HPLC) method has been developed for determination of tolterodine tartrate. Mobile phase was composed of phosphate acetate $0.1 \mathrm{M}(\mathrm{pH} 2.5)$-acetonitrile $(50: 50 \mathrm{v} / \mathrm{v})$ with a flow rate of $1.2 \mathrm{ml} / \mathrm{min}$. The eluted peaks were detected by a UV detector was set at wavelength of $285 \mathrm{~nm}$. The method was validated in the range of tolterodine tartrate concentrations from 10 to $100 \mu \mathrm{g} / \mathrm{ml}$. The limits of detection (LOD) and quantitation (LOQ) of the method were 5 and $10 \mu \mathrm{g} / \mathrm{ml}$, respectively. The average drug recovery was $98.20 \%$ throughout the linear concentration range. The average within-run and between-run accuracy values of $98.56 \%$ and $99.11 \%$ respectively. Statistical assessment of various in vitro dissolution parameters and assay results was also conducted to establish if there were any significant difference among them. The validated HPLC method has been used successfully to study tolterodine tartrate.
\end{abstract}

Keywords: Tolterodine tartrate, HPLC, assay, dissolution

\section{Introduction}

Tolterodine tartrate, $(R)-N, N$-diisopropyl-3(2-hydroxy- 5-methylphenyl)-3-phenylpropanamine 1-hydrogen tartrate (Fig. 1), is a new, potent and competitive muscarinic receptor antagonist in clinical development for the treatment of urge incontinence and other symptoms of unstable bladder (1-3). Tolterodine has a high affinity and specificity for muscarinic receptors in vitro and exhibits the selectivity for the urinary bladder over salivary glands in vivo, so it has the advantageous tolerability profile in terms of the low frequency of bothersome dry mouth (4). After oral administration, tolterodine is metabolized in liver, resulting in the formation of the 5-hydroxymethyl derivative, a major pharmacologically active metabolite (5). However, a small proportion 
<smiles>Cc1ccc(O)c(C(CCN(C(C)C)C(C)CCO)c2ccccc2)c1</smiles>

Figure1 Chemichal structure of tolterodine tartrate

of Caucasians showed a pharmacokinetic profile in accordance with poor metabolizers, having about ten time's higher tolterodine concentrations but no measurable concentrations of the 5-hydroxymethyl derivative (6-8). The therapeutic dose of tolterodine tartrate is only $4 \mathrm{mg}$ every day given orally and the test tablet in this experiment is an extended-release formation, so the concentration of tolterodine tartrate in human plasma is very low, a sensitive analytical method is needed for its determination in plasma (9). Kumar et al. developed an isocratic chiral HPLC method for the separation of tolterodine tartrate enantiomers but did not refer to determination in human plasma (10). Vinay et al. established a gas chromatography mass spectrometry (GC-MS) method to quantification of tolterodine, the limit of quantification (LOQ) in plasma of the method was only $0.5 \mathrm{ng} / \mathrm{ml}$ and it was insufficiently sensitive to enable full pharmacokinetics profiling of tolterodine tartrate (11). Swart et al. developed a capillary column LC switching system coupled to electrospray ionization-tandem mass spectrometry for quantification of free drug concentrations of tolterodine and two metabolites in plasma, the LOQ was 0.05 $\mathrm{ng} / \mathrm{ml}$, but the analysis time was long (12); then they improved their experience with the solid-phase extraction (SPE) coupled directly to mass spectrometry (MS) method which reduced the analysis time (13). Previously, we studied bioavailability and bioequivalence of some drugs such as ezetimibe, amlodipine, atorvastatin, enalapril, cellcept by liquid chromatography mass spectrometry (LC-MS) and HPLC methods in human plasma (14-22). In this study, we describe a more simple, selective and highly sensitive method by using high performance liquid chromatography for the determination of tolterodine tartrate in human plasma.

\section{Materials and methods}

\section{Materials}

Tolterodine tartrate extended release test tablets (batch no. 014, Tehran- darou), tolterodine tartrate reference tablets (batch no. N771F, and tolterodine tartrate reference standard (99.9\% purity) were supplied and identified by Pharmacia, Upjohn (Italy). Acetonitrile was HPLC grade and was purchased from Merck (Merck Company, Germany). Other chemicals were all of analytical grade and were used as received. Water was purified by re distillation before use.

\section{Instrument and HPLC method}

The HPLC system to include of pump (KNAUER, model 1000, Germany), wavelength UV detector (KNAUER, model 2800(DAD), Germany) used at a wavelength of $285 \mathrm{~nm}$ with the outputs to record and analyze using with a software (Chrome Gate, KNAUER, Germany). The 
drug analization was performed using a C18 analytical column $(250 \mathrm{~mm} \times 4.6 \mathrm{~mm}$, particle size $5 \mu \mathrm{m}$; Perfectsill, MZAnalysente chnik, Germany) equipped by a guard column of the same packing. The mobile phase was composed of acetate buffer ( $\mathrm{pH}$ 2.5)-acetonitrile (50:50 v/v) with a flow rate of $1.2 \mathrm{ml} / \mathrm{min}$. Sample injection to system $(50 \mu \mathrm{L})$ was made by a loop injector (Rheodyne ${ }^{\circledR} 7725 i$, Cotati, CA, USA).

\section{Preparation of stock solutions}

Stock solutions of tolterodine tartrate was prepared in HPLC mobile phase at concentrations of $1 \mathrm{mg} / \mathrm{ml}$ and were stored at $4{ }^{\circ} \mathrm{C}$.Working solutions of tolterodine tartrate were prepareddaily in HPLC mobile phase by appropriate dilution at 5.0,10.0, 25.0, 50.0, 100.0, 250.0, 500.0, 1000, and $1500 \mu \mathrm{g} / \mathrm{ml}$.

Estimation of tolterodine tartrate in tablet dosage form

Each tablet contains $2 \mathrm{mg}$ of tolterodine tartrate. Twenty tablets were taken and weighed accurately. The average weight of one tablet was calculated and powdered. Equivalent to $2 \mathrm{mg}$ of tolterodine tartrate of powder was taken and transferred to a $100 \mathrm{~mL}$ volumetric flask and about 75 $\mathrm{mL}$ of phosphate buffer at $\mathrm{pH} 1.2$ was added and sonicated to dissolve. The volume was made up to the mark with phosphate buffer. The solution was filtered through a membrane filter $(0.22 \mu \mathrm{m})$ and sonicated to degas. Then $5 \mathrm{~mL}$ of above solution was pipetted out in $50 \mathrm{~mL}$ volumetric flask and volume was made up to the mark with phosphate buffer. The prepared solution was injected into the HPLC system and the observation was recorded.

\section{Dissolution test}

The dissolution test was undertaken using tablet dissolution tester in 6 replicates for each brand. Dissolution media were USP buffer solutions at $\mathrm{pH} 1.2$ (phosphate buffer solution). The medium was maintained at $37 \pm 0.5^{\circ} \mathrm{C}$. In all the experiments, $5 \mathrm{~mL}$ of dissolution sample was withdrawn at 0 , $10,20,30,40,50$ and $60 \mathrm{~min}$ and replaced with equal volume to maintain sink condition. Samples were filtered and assayed by HPLC method. The concentration of each sample was determined from a calibration curve obtained from pure samples of tolterodine tartrate.

\section{Method validation}

The method was validated for selectivity, linearity, accuracy, precision, recovery, stability, detection limit and quantization limit according to the principles of the FDA industry guidance (23-30).

\section{Assay specificity}

To evaluate the matrix effect on the ionization of analyses, five different concentration levels of tolterodine tartrate $(5$, $10,20,30,40,50$, and $100.0 \mu \mathrm{g} / \mathrm{ml})$ were prepared in the drug-free blank plasma as five sample series using five different lots of the drug-free plasma and the samples were processed, as described, and injected to HPLC. Standard curves of ten concentrations of tolterodine tartrateranged $10-100.0 \mu \mathrm{g} / \mathrm{ml}$ were assayed. The limit of 
detection (LOD) was estimated from the signal-to- noise ratio. This parameter was defined as the lowest concentration level resulting in a peak area of three times the baseline noise.

\section{Precision and accuracy Within-run variations}

In one run, three samples with concentrations of 10,50 , and $100 \mu \mathrm{g} / \mathrm{ml}$ (from high, middle, and low regions of the standard curve) were prepared in triplicate and analyzed by developed HPLC method. Then, the coefficient of variations (\%CV) of the corresponding determined concentrations were calculated in each case.

\section{Between-run variations}

On three different runs, samples from upper, intermediate, and lower concentration regions used for construction of standard curve were prepared and analyzed by HPLC method. Then, the corresponding \%CV values were calculated.

\section{Extraction recovery}

Three samples with concentrations of 10, 50, and $100 \mu \mathrm{g} / \mathrm{ml}$ (from high, middle and low regions of the standard curve) were prepared in triplicate and analyzed by developed HPLC method. Then, the ratio of the recorded peak heights to the peak heights resulted from the direct injection of the aqueous solutions of toltrodine with the same concentrations were determined as percentage in each case.

\section{Stability}

Freeze and thaw stability: Three concentration levels of QC samples were stored at the storage temperature $\left(-20{ }^{\circ} \mathrm{C}\right)$ for $24 \mathrm{~h}$ and thawed unassisted at room temperature. When completely thawed, the samples were refrozen for $24 \mathrm{~h}$ under the same conditions. The freeze-thaw cycle were repeated twice, then the samples were tested after three freeze $\left(-20{ }^{\circ}\right.$ )-thaw (room temperature).

Short-term temperature stability: Three concentration levels of QC samples were kept at room temperaturefor a period that exceeded the routine preparation time of samples (around 6h).

Long-term stability: Three concentration levels of QC samples kept at low temperature $\left(-20^{\circ}\right.$ C) were studied for a period of 4 weeks.

Post-preparative stability: The auto sampler stabilitywas conducted reanalyzing extracted QC samples keptunder the auto sampler conditions $\left(4^{\mathrm{C}}\right)$ for $12 \mathrm{~h}$.

\section{Results}

\section{Method development}

In response to lack of an accessible, consistent, and simpletouse analysis method for tolterodine tartrateassay in plasma as an vital part of pharmacokinetic and bioequivalence estimate projects on the drug we urbanized a simple and offered HPLC method with UV detection based on the available equipments found in most pharmaceutical laboratories. To this end, initially a series of isocratic as well as gradient conditions using different usual mobile phase compositions, polarities, ionic strengths, and $\mathrm{pH}$ values were tested in order to determine the best condition for the analyte separation. 
System suitability tests

The number of theoretical plates $(\mathrm{N})$, peak symmetry, and retain ability $\left(\mathrm{K}^{\prime}\right)$ of the method for tolterodine tartratewere 1296, 1.143 , and 2.75 , respectively. These data show that the developed method is of appropriate separation efficiency and peak shape, both of which are important factors in estimate of the chromatographic method outputs. Typical chromatograms produced from the developed method are shown in figure 2. Figure 2.A shows are presentative chromatogram of a sample obtained at $7 \mathrm{~h}$ from a subject who received a single oral dose $(2 \mathrm{mg})$, no interferences of the analyst were observed and the retention times of tolterodine tartratewas $4.98 \mathrm{~min}$ and the total HPLC analysis time was 7 min per sample. The HPLC chromatogram for a blank sample indicating no endogenous peaks at the retention positions of tolterodine tartrate was shown in figure 2.B.

\section{Linearity}

The method produced linear responses throughout the tolterodine tartrate concentration range of $10-100 \mu \mathrm{g} / \mathrm{ml}$, which is suitable for intended purposes. A typical linear regression equation of the method was: $\mathrm{y}=7.345 \mathrm{x}+0.0234$, with $\mathrm{x}$ and $\mathrm{y}$ representing tolterodine tartrateconcentration (in $\mathrm{mcg} / \mathrm{ml}$ ) and peak height (in arbitrary units), respectively, and the regression coefficient $\left(r^{2}\right)$ of 0.9942 . The lower limit of quantification for tolterodine tartratewas proved to be $10 \mu \mathrm{g} / \mathrm{ml}$ and the lower limit of detection was $5 \mu \mathrm{g} / \mathrm{ml}$. Figure 2.B shows the chromatogram of an extracted sample that contained $20 \mu \mathrm{g} / \mathrm{ml}$ of tolterodine tartrate.

\section{Within-run variations and accuracy}

The within-run variations of the developed HPLC method as well as the corresponding absolute recoveries are shown in table 1 .

(A)

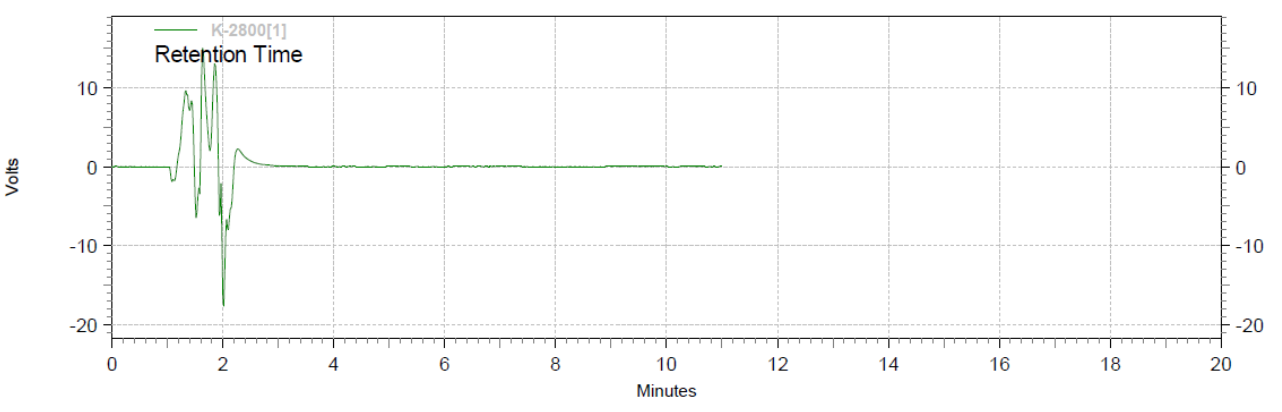

(B)

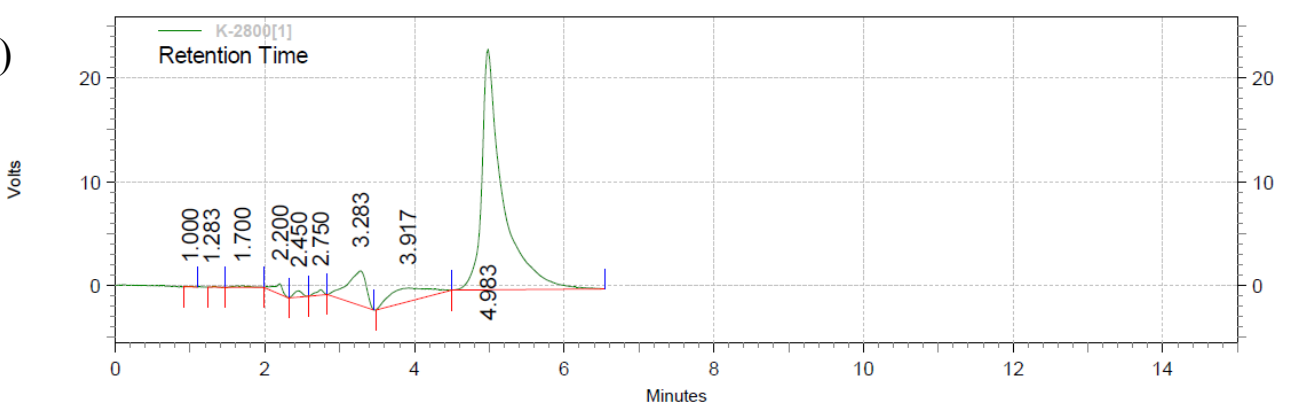

Figure2 Chromatogarm of samples: A: Blank B: chromatogram of an extracted sample that contained $20 \mu \mathrm{g} / \mathrm{ml}$ of tolterodine tartrate. 


\section{Between-run variations and accuracy}

The between-run variations of the developed HPLC method as well as the corresponding absolute recoveries are shown in table 2 .

Table 1 Within-run variations and accuracy of the LC-Mass method for quantitation of Tolterodine $(\mathrm{n}=3)$.

\begin{tabular}{ccc}
\hline $\begin{array}{c}\text { Nominal } \\
\text { added } \\
\text { concentration } \\
(\mu \mathrm{g} / \mathrm{ml})\end{array}$ & $\begin{array}{c}\text { Sample } \\
\text { number }\end{array}$ & Mean \pm SD \\
\hline 10 & 1 & $9.91 \pm 0.015$ \\
& 2 & \\
\hline 50 & 3 & $50.13 \pm 0.23$ \\
& 1 & \\
\hline 100 & 2 & $100.01 \pm 0.077$ \\
& 3 & \\
\hline
\end{tabular}

Table 2 Between-run variations and accuracy of the HPLC method for quantitation of tolterodine $(\mathrm{n}=3)$

\begin{tabular}{ccc}
\hline $\begin{array}{c}\text { Nominal } \\
\text { added } \\
\text { concentration } \\
(\boldsymbol{\mu g} / \mathbf{m l})\end{array}$ & $\begin{array}{c}\text { Run } \\
\text { number }\end{array}$ & Mean \pm SD \\
\hline 10 & 1 & $10.1 \pm 0.015$ \\
& 2 & \\
\hline 50 & 3 & \\
& 1 & $49.99 \pm 0.17$ \\
& 2 & \\
\hline 100 & 1 & $100.16 \pm 0.084$ \\
& 2 & \\
\hline
\end{tabular}

\section{Extraction recovery}

The extraction recovery determined for tolterodine tartrate was shown to be consistent, precise and reproducible. Data was shown below in table 3 .

\section{Stability}

Table 4 summarizes the freeze and thaw stability, short term stability, long-term stability and post-preparative stability data of tolterodine tartrate. All the results showed the stability behavior during these tests and there were no stability related problems during the samples routine analysis for the pharmacokinetic, bioavailability or bioequivalence studies. The stability of working solutions was tested at room temperature for $6 \mathrm{~h}$. based on the results obtained, these working solutions were stable within $6 \mathrm{~h}$.

Estimation of tolterodine tartrate in tablet dosage form

The percent content of tolterodine tartratein tablet dosage form was found to be $100.25 \%$. The USP specifications for assay are that the tolterodine tartratecontent should be less than $90 \%$ and not more than $110 \%$. Therefore, the assay results ascertain the presence and compendia quality of tolterodine tartrate in all these products (Table 5).

\section{In vitro drug release study}

The release profiles of different brands of tolterodine tartrate tablets are shown in figure 3 and table 6, 7. All dissolution data are based on the actual drug content of the test tablets as calculated from the assay results. Around $80 \%$ drug was released 
Table 3 Relative recovery of Tolterodine by the HPLC method $(n=3)$

\begin{tabular}{ccc}
\hline $\begin{array}{c}\text { Nominal added } \\
\text { concentration } \\
(\boldsymbol{\mu g} / \mathbf{m l})\end{array}$ & $\begin{array}{c}\text { Sample } \\
\text { number }\end{array}$ & Mean \pm SD \\
\hline \multirow{2}{*}{10} & 1 & \\
& 2 & $97.21 \pm 1.84$ \\
50 & 3 & \\
& 1 & \\
\hline & 2 & $94.18 \pm 1.58$ \\
\hline & 3 & \\
\hline & 1 & $96.67 \pm 0.35$ \\
\hline
\end{tabular}

Table 4 Data showing stability of tolterodine tartrate at different QC levels $(n=5)$

\begin{tabular}{cccc}
\hline & $\mathbf{1 0}(\boldsymbol{\mu g} / \mathbf{m l})$ & $\mathbf{5 0}(\boldsymbol{\mu g} / \mathbf{m l})$ & $\mathbf{1 0 0}(\boldsymbol{\mu g} / \mathbf{m l})$ \\
& Mean \pm SD & Mean \pm SD & Mean \pm SD \\
& & & \\
\hline Short-term stability & $95.21 \pm 2.12$ & $94.65 \pm 4.76$ & $95.68 \pm 6.21$ \\
& & & \\
\hline Freeze and thaw stability & $97.56 \pm 3.98$ & $96.23 \pm 3.12$ & $96.63 \pm 3.65$ \\
& & & \\
\hline Long-term stability & $93.68 \pm 2.21$ & $97.65 \pm 1.54$ & $97.32 \pm 4.32$ \\
& & & \\
\hline Post-preparative stability & $91.32 \pm 1.87$ & $92.21 \pm 2.54$ & $92.21 \pm 1.12$
\end{tabular}

Table 5 Assay of tolterodine tartrate

\begin{tabular}{ccccccccccccc}
\hline Number & $\mathbf{1}$ & $\mathbf{2}$ & $\mathbf{3}$ & $\mathbf{4}$ & $\mathbf{5}$ & $\mathbf{6}$ & $\mathbf{7}$ & $\mathbf{8}$ & $\mathbf{9}$ & $\mathbf{1 0}$ & Mean \pm SD & RSD \\
\hline $\begin{array}{c}\text { Percentage } \\
\text { of label }\end{array}$ & 99.7 & 1045 & 1024 & 101 & 102.6 & 102.6 & 1035 & 104.8 & 103.5 & 104.5 & $100.25 \pm 1.6$ & 157 \\
\begin{tabular}{c} 
claimed \\
\hline
\end{tabular} & & & & & & & & & & & & \\
\hline
\end{tabular}




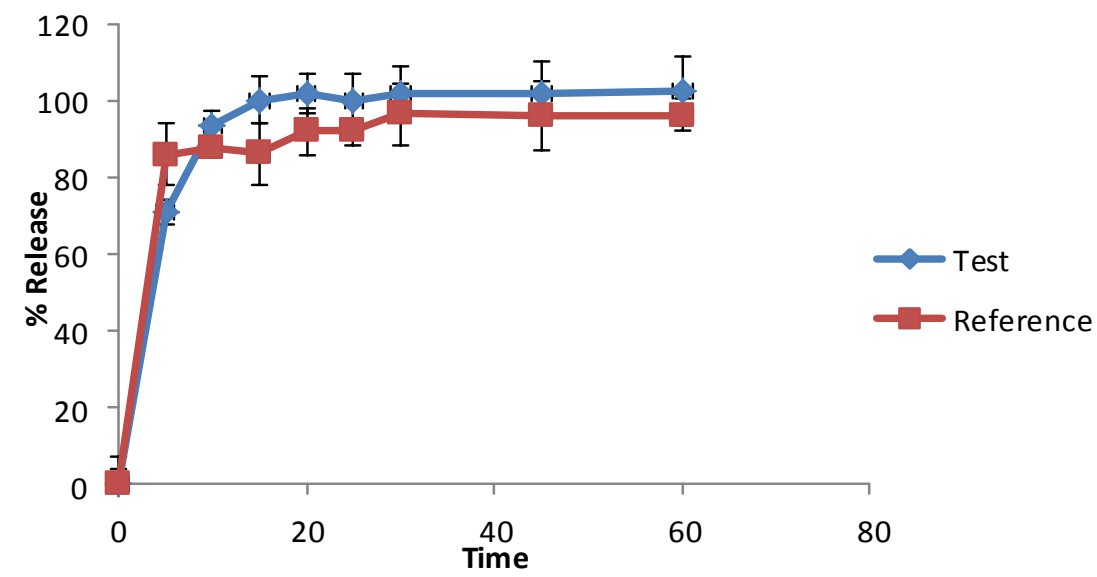

Figure 3 Diagram dissolution of tolterodine tartrate for test and reference sample

Table 6 Dissolution of tolterodine tartrate for test sample

\begin{tabular}{cccccccccc}
\hline Time & $\mathbf{1}$ & $\mathbf{2}$ & $\mathbf{3}$ & $\mathbf{4}$ & $\mathbf{5}$ & $\mathbf{6}$ & Mean \pm SD & SD & RSD \\
$(\mathbf{m i n})$ & & & & & & & & & \\
\hline 5 & 68.07 & 89.24 & 42.09 & 49.22 & 90.80 & 85.76 & $70.86 \pm 21.27$ & 21.27 & 30.01 \\
\hline 10 & 106.54 & 97.27 & 79.25 & 85.87 & 95.85 & 98.49 & $93.88 \pm 9.75$ & 9.75 & 10.38 \\
\hline 15 & 103.43 & 100.49 & 106.09 & 97.82 & 95.38 & 98.92 & $100.36 \pm 3.89$ & 3.89 & 3.87 \\
\hline 20 & 98.02 & 101.18 & 117.96 & 99.82 & 96.00 & 99.67 & $102.11 \pm 7.97$ & 7.97 & 7.80 \\
\hline 25 & 103.39 & 95.33 & 106.79 & 100.11 & 96.64 & 100.06 & $100.39 \pm 4.24$ & 4.24 & 4.22 \\
\hline 30 & 106.99 & 99.26 & 107.59 & 100.87 & 97.32 & 100.96 & $102.16 \pm 4.19$ & 4.19 & 4.10 \\
\hline 45 & 107.58 & 99.08 & 103.60 & 103.51 & 96.44 & 103.06 & $102.21 \pm 3.91$ & 3.91 & 3.82 \\
\hline 60 & 111.41 & 98.95 & 101.21 & 102.12 & 98.49 & 104.09 & $102.71 \pm 4.74$ & 4.74 & 4.61 \\
\hline
\end{tabular}


Table 7 Dissolution of tolterodine tartrate for reference sample

\begin{tabular}{ccccccccc}
\hline Time (min) & $\mathbf{1}$ & $\mathbf{2}$ & $\mathbf{3}$ & $\mathbf{4}$ & $\mathbf{5}$ & $\mathbf{6}$ & Mean $\mathbf{4 S D}$ & RSD \\
\hline 5 & 96.53 & 89.90 & 51.46 & 92.35 & 93.80 & 92.77 & $86.13 \pm 17.12$ & 19.88 \\
\hline 10 & 105.60 & 92.98 & 45.94 & 94.71 & 94.45 & 95.12 & $88.13 \pm 21.17$ & 24.02 \\
\hline 15 & 92.41 & 89.40 & 47.20 & 98.32 & 96.67 & 95.26 & $86.54 \pm 19.53$ & 22.57 \\
\hline 20 & 100.97 & 88.27 & 69.35 & 99.70 & 98.18 & 97.00 & $92.25 \pm 12.08$ & 13.09 \\
\hline 25 & 92.89 & 92.29 & 69.26 & 101.44 & 99.52 & 98.20 & $92.27 \pm 11.85$ & 12.84 \\
\hline 30 & 99.32 & 85.93 & 86.98 & 102.22 & 105.61 & 100.06 & $96.69 \pm 8.23$ & 8.51 \\
\hline 45 & 100.79 & 85.30 & 81.97 & 104.08 & 103.92 & 100.59 & $96.11 \pm 9.83$ & 10.23 \\
\hline 60 & 100.55 & 94.34 & 80.53 & 103.81 & 97.24 & 102.32 & $96.46 \pm 8.53$ & 8.84 \\
\hline
\end{tabular}

within $30 \mathrm{~min}$ and almost 100\% drug was released within $60 \mathrm{~min}$ from all the brands in phosphate buffer.

\section{Discussion}

Tolterodine has a high affinity and specificity for muscarinic receptors in vitro and exhibits the selectivity for the urinary bladder over salivary glands in vivo, so it has the advantageous tolerability profile in terms of the low frequency of bothersome dry mouth (1-3). Several bioanalytical methods are reported to determine tolterodine tartrate in different biological matrices like plasma, serum, urine, and cerebrospinal fluids (6-8). Although these methods were sufficiently sensitive, they were not suitable for most laboratories to perform studies involving samples in high through-put for therapeutic monitoring (9). In the present study, we describe a simple, selective and high-through put method using HPLC for the estimation of tolterodine tartrate. The method was fully validated and applied successfully to quantify the drug in pharmaceutical dosage form. A short chromatographic run time of 7 min allows the quantification of tolterodine tartrate in bulk raw material, tablet dosage form in quality control laboratories, and is compatible with LC-MS technique where there is no need for traditional HPLC methods with complex mobile phase mixtures, long chromatographic run times and more solvent consumed methods. The developed RP-HPLC technique will eliminate significant time and cost per sample from analytical process while improving the quality of results. Statistical 
assessment of various in vitro dissolution parameters and assay results was also conducted to establish if there were any significant difference among them. The validated HPLC method has been used successfully to study tolterodine tartrate. The validation tests on the developed method showed acceptable degree of linearity, sensitivity, precision, accuracy and recovery for the method.

\section{Conclusion}

A sensitive, selective, accurate and precise HPLC method was developed and validated for determination of tolterodine tartrate. The reported method offers several advantages makes the method suitable for the analysis of large sample batches resulting from the pharmacokinetic, bioavailability or bioequivalent study of tolterodine tartrate.

\section{Acknowledgement}

The authors would like to thank the authority of the Faculty of Pharmacy, Zanjan University of Medical Sciences, for their support. The authors wish to thank Tehran Darou Pharmaceuticals (Tehran, Iran) for kindly providing us by tolterodine tarterate samples.

\section{Conflict of interest}

The authors declared no potential conflict of interest with respect to the authorship, and/or publication of this study.

\section{References}

1. Wefer J, Truss MC, Jonas U. Tolterodine: an overview. World J Urol 2001;19:312-18.

2. Hills CJ, Winter SA, Balfour JA. Tolterodine. Drugs 1998;55:813-20.

3. Palmer L, Anderson L, Anderson T, Stenberg U. Determination of Tolterodine and the hydroxymethyl metabolite in plasma, serum and urine using gas chromatography-mass spectrometry. J Pharm Biomed Anal 1997; 16:155-65.

4. Zhang B, Zhang Z, Tian Y, Xu F. High performance liquid chromatography-electro spray ionization mass spectrometric determination of Tolterodine tartarate in human plasma. J Chromatogr B 2005;824:92-8.

5. Dwibhashyam VS, Keerthi P, Ratna JV, Nagappa AN. Reverse-phase, high performance liquid chromatographic method for the determination of Tolterodine Tartarate in routine Quality control sample. J Pharm Sci Technol 2009;63:234-39.

6. Nilvebrant L, Gillberg PG, Sparf B. Antimuscarinic potency and bladder selectivity of PNU-200577, a major metabolite of tolterodine. Pharmacol Toxicol 1997;81:169-72.

7. Xia ZL, Chen ZY, Yao TW. An enantio specific HPLC method for the determination of (S)enantiomer impurities in (R)-tolterodine tartarate. Pharmazie 2007; 62:170-73.

8. Nilvebrant L. Tolterodine and its active 5hydroxymethyl metabolite: pure muscarinic receptor antagonists. Pharmacol Toxicol 2002; 90: 260-67.

9. Krishna SR, Rao BM, Rao NS. A validation stability-indicating HPLC method for the determination of related substance and assay of Tolterodine Tartarate. Rasayan J Chem 2009;2: $144-50$.

10. Kumar YR, Ramulu G, Vevakanand VV, Vaidyanathan G, Srinivas K, Kumar MK, et al. A validated chiral HPLC method for the enantiomeric separation of Tolterodine tartarate. J Pharm Biomed Anal 2004; 35:1279-85.

11. Vinay S, Zahid Z, Mazhar F. Stability indicating HPLC determination of Tolterodine tartarate in pharmaceutical dosage form. Indian $\mathrm{J}$ Chem Technol 2006;13:242-46.

12. Swart R, Koivisto P, Markides KE. Capillary solidphase extraction-tandem mass spectrometry for fast quantification of free concentrations of tolterodine and two metabolites in ultra filtered plasma samples. J Chromatogr B 1999;736:247-53.

13. Swart R, Koivisto P, Markides KE. Column switching in capillary liquid chromatographytandem mass spectrometry for the quantitation of $\mathrm{pg} / \mathrm{ml}$ concentrations of the free basic drug tolterodine and its active 5-hydroxymethyl metabolite in microlitre volumes of plasma. $\mathrm{J}$ Chromatogr A 1998;828:209-18.

14. Danafar H, Hamidi M. Pharmacokinetics and Bioequivalence Study of Amlodipine and 
Atorvastatin in Healthy Male Volunteers by LCMS. Pharm Sci 2015;21:167-74.

15. Danafar H, Hamidi M. Simple and Sensitive High-Performance Liquid Chromatography (HPLC) Method with UV Detection for Mycophenolic Acid Assay in Human Plasma. Application to a Bioequivalence Study. Adv Pharm Bull 2015;5:563-8.

16. Danafar H, Hamidi M. Liquid chromatographytandem mass spectrometry (LC-MS) method for the assignment of enalapril and enalaprilat in human plasma. Pharm Biomed Res 2015; 1: 4758.

17. Danafar H, Hamidi M. Simple and sensitive high performance liquid chromatographic method for the simultaneous quantitation of the phenylalanine in human plasma. Pharm Biomed Res 2015;1:12-20.

18. Danafar H, Hamidi M. A Rapid and Sensitive LC-MS Method for Determination of ezetimibe Concentration in Human Plasma: Application to a Bioequivalence Study. Chromatographia 2013;76:1667-75.

19. Danafar $\mathrm{H}$. Method validation of colonidine in human plasma by LC-MS. Pharm Biomed Res 2015;1:48-58.

20. Danafar H, Hamidi M.LC-MS Method for Studying the Pharmacokinetics and Bioequivalence of ClonidineHydrochloride in Healthy Male Volunteers. Avicenna J Med Biotech 2016;8:91-8

21. Danafar $\mathrm{H}$. A quick and easy high performance liquid chromatography method for evaluation of cefixime in human plasma. Pharm Biomed Res 2015;1:29-39.

22. Danafar H, Hamidi, M. A quick and sensitive liquid chromatography-tandem mass spectrometry (LC-MS) method for the determination of enalapril and enalaprilat in human plasma: Application to a Bioequivalence Study. Iran J pharm sci 2014;10:21-34.
23. FDA, "Guidance for Analytical Procedures and Methods Validation for Drugs and Biologics Guidance for Industry 2015..http://www.fda.gov/BiologicsBloodVaccin es/GuidanceComplianceRegulatoryInformation/ Guidances/defaulthtm

24. http://en.wikipedia.org/wiki/Tolterodine

25. http://www.rxlist.com/detrol-la-drug.htm

26. Nanda R.K, Gaikwad J, Prakash A. Simultaneous spectrophotometric Estimation of Tolterodine on Pharmaceutical Dosage form. Research J pharma \& Tech 2009;2:312-4.

27. Nanda RK, Gaikwad J, Prakash A. Estimation of Tamsulosin and Tolterodine in its pharmaceutical dosage form by Spectrophotometric method. Int J pharma Tech Res 2009;1:420-3.

28. Vinay S, Zahid Z. Stability -indicating HPLC determination of Tolterodinetartrate in pharmaceutical dosage forms. Indian J Che Tech 2006;13:242-46.

29. Krishna SR, Rao BM, Rao NS, A validation stability - indicating HPLC method for thedetermination of related substance and assay of Tolterodine Tartarate. Rasayan J Chem 2009;2:144-50.

30. Murthy VSN, Keerthy P, Ratanal JV, Nagappa AN. Reverse - phase, high performance liquidchromatographic method for the determination of Tolterodine Tartarate in routin Quality controlsample. J Pharm Sci \& Tech 2009;63:234-9. 